\title{
Effects of pet exposure in the first year of life on respiratory and allergic symptoms in 7-yr-old children. The SIDRIA-2 study
}

Lombardi E, Simoni M, La Grutta S, Viegi G, Bisanti L, Chellini E, Dell'Orco V, Migliore E, Petronio MG, Pistelli R, Rusconi F, Sestini P, Forastiere F, Galassi C and the SIDRIA-2 Collaborative Group. Effects of pet exposure in the first year of life on respiratory and allergic symptoms in 7-yr-old children. The SIDRIA-2 study.

Pediatr Allergy Immunol 2010: 21: 268-276.

(C) 2009 John Wiley \& Sons A/S

The effects of pet exposure on the development of respiratory symptoms have recently been the matter of vivid discussion. Our objective was to determine the effects of exposure to cat or dog in the first year of life on subsequent respiratory/allergic symptoms in children in a large Italian multicentre study. As part of the SIDRIA-2 Study (Studi Italiani sui Disturbi Respiratori dell'Infanzia e l'Ambiente 2002), the parents of 20016 children (median age $7 \mathrm{yr}$ ) provided information on indoor exposures at different times in life and respiratory/allergic symptoms through questionnaires. Logistic regression analyses were performed taking into account cat or dog exposure at different times in life and adjusting for the presence of the other pet, mould exposure, gender, age, parental education, maternal smoking during the first year of life, current passive smoking, family history of asthma/rhinitis/eczema and other potential confounders. Neither significant effects of dog exposure in the first year of life nor in other periods were found on respiratory/ allergic symptoms after adjusting for the other covariates. Cat exposure in the first year of life was significantly and independently associated with current wheezing [OR (95\% CI) $1.88(1.33-2.68), \mathrm{p}<0.001]$ and current asthma [1.74 (1.10-2.78), $\mathrm{p}<0.05]$ and border-line associated with current rhinoconjunctivitis [1.43 (0.97-2.11), $\mathrm{p}=0.07]$. No other effects of cat exposure were found on respiratory/allergic symptoms. Cat, but not dog, exposure in the first year of life is an independent risk factor for current wheezing, current asthma and current rhinoconjunctivitis at the age of 7 .

\section{Enrico Lombardi ${ }^{1}$, Marzia Simoni ${ }^{2}$, Stefania La Grutta ${ }^{3,4}$, Giovanni Viegi ${ }^{2,4}$, Luigi Bisanti ${ }^{5}$, Elisabetta Chellini' ${ }^{6}$, Valerio Dell'Orco ${ }^{7}$, Enrica Migliore $^{8}$, Maria Grazia Petronio', Riccardo Pistelli ${ }^{10}$, Franca Rusconi ${ }^{11}$, Piersante Sestini ${ }^{12}$, Francesco Forastiere $^{13}$, Claudia Galass $i^{8}$ and the SIDRIA-2 Collaborative Group ${ }^{14}$}

${ }^{1}$ Section of Respiratory Medicine, Department of Paediatrics, University of Florence, 'Anna Meyer' Children's University Hospital, Florence, Italy, ${ }^{2}$ Pulmonary Environmental Epidemiology Unit, National Research Council Institute of Clinical Physiology, Pisa, Italy, ${ }^{3}$ Pediatric Pulmonology and Allergology Service, ARNAS (Azienda di Rilievo Nazionale ad Alta Specializzazione), Palermo, Italy, ${ }^{4}$ IBIM (Istituto di Biomedicina e Immunologia Molecolare), National Research Council, Palermo, Italy, ${ }^{5}$ Department of Epidemiology, Milan Health Authority, Milan, Italy, ${ }^{6}$ Unit of Environmental and Occupational Epidemiology, Istituto

Scientifico Prevenzione Oncologica (CSPO), Florence, Italy, ${ }^{7}$ Department of Prevention, Roma G Local Health Authority, Tivoli, Rome, Italy, ${ }^{8}$ Unit of Cancer Epidemiology, ASO San Giovanni Battista, University of Turin, CPO Piemonte, Turin, Italy, ${ }^{9}$ Unit of Hygiene and Public Health, Department of Prevention, Local Health Authority 11, Empoli, Florence, Italy, ${ }^{10}$ Department of Respiratory Physiology, Catholic University, Rome, Italy, ${ }^{11}$ Unit of Epidemiology, 'Anna Meyer' Children's University Hospital, Florence, Italy,

${ }^{12}$ Section of Respiratory Diseases, Department of Clinical Medicine and Immunological Sciences, University of Siena, Siena, Italy, ${ }^{13}$ Department of Epidemiology, Rome E Health Authority, Rome, Italy, ${ }^{14}$ The SIDRIA-2 Collaborative Group: Ciccone G, Migliore E, Mirabelli D (CPO, Torino); Berti G and Cadum E (ARPA, Torino); Bugiani $\mathrm{M}$ and Piccioni $\mathrm{P}$ (CPA, ASL 4, Torino); Bisanti L and Russo A (ASL Milano); Bellasio M (Università di Milano); Gianelle V (ARPA, Milano); Piffer S, Battisti L, Kaisermann D and Gentilini M (APSS di Trento); Giannella $G$ and Talassi F (ASL di Mantova); Galassi C (ASR, Emilia RomagnaCPO, Torino); Caranci N (ASR, Emilia Romagna-ASL 5, Torino); Frasca G and Biocca M (ASR, Emilia Romagna); De Munari E (ARPA, Emilia Romagna); Chellini E (CSPO, Firenze); Lombardi $E$ and Rusconi $F$ (AOU Meyer, Firenze); Biggeri A and Gabellini C (Università di Firenze), Grechi D (ARPAT, Firenze); 


\author{
Petronio MG (ASL di Empoli); Sestini P (Università di \\ Siena); Viegi $G$ and Simoni M (CNR, Pisa, and IBIM- \\ CNR, Palermo); Forastiere F, De Sario M, Agabiti N \\ (ASL RM/E, Roma); Pistelli $R$ and Corbo $G$ (Università \\ S. Cuore, Roma); Bonci $E$ and Indinnimeo L (ISS, \\ Roma); Dell'Orco V (ASL RM/G, Roma); Armenio L, \\ Brunetti L, Cavone M, Lospalluti ML, Massagli M, \\ Polieri G, Rizzi D, Rana FR and Rana M (Università di \\ Bari); La Grutta S (ARNAS and IBIM-CNR, Palermo) \\ Key words: asthma; cat; children; dog; rhinitis; \\ wheezing \\ Enrico Lombardi, Section of Respiratory Medicine, \\ ‘Anna Meyer' Children's University Hospital, Viale G. \\ Pieraccini 24, 50139 Florence, Italy \\ Tel.: +39055 5662461 \\ Fax: +39055 5662400 \\ E-mail: e.lombardi@meyer.it \\ Accepted 18 April 2009
}

The effects of family pet exposure on the development of respiratory and allergic symptoms have recently been the matter of vivid discussion. Although for several years the presence of dogs and cats at home has been considered a risk factor for the subsequent development of respiratory and allergic symptoms, recent studies have questioned this harmful role of family pets. The studies on this topic have so far given contradicting results. Some studies have shown a higher prevalence of allergic sensitization and respiratory illness in children with dogs or cats at home (1-5) and a systematic review of the literature by Apelberg et al. (6), based on articles published between 1966 and 1999, concluded that pet exposure was a significant risk factor for subsequent asthma and wheezing in children older than 6. Other studies, however, could not find this relationship between pet exposure and subsequent respiratory symptoms, or even found a protective effect of dogs and cats on the subsequent development of respiratory symptoms or allergic sensitization (7-12).

The comparison of such studies is often difficult, because of differences in study design and outcomes. One of the main points is the confusion between allergic sensitization and respiratory/allergic symptoms. Although chronic childhood atopy is associated with the most significant forms of childhood wheezing (13), the relationship between atopic sensitization and clinical allergic disease remains incompletely understood (14). Furthermore, where the atopic sensitization is absent, numerous environmental factors plus genetic predisposition may assume importance for wheezing (13). In the present study, we focused our attention on the respiratory/allergic symptoms rather than allergic sensitization.

Another important issue when interpreting the studies on pet exposure and respiratory/ allergic disease is that the protective effect of family pets on allergic disease reported by several prospective birth cohort studies might in part be attributable to the removal of pets in families with sensitized or symptomatic children or in families with a positive history for atopy at the time the child was born (15). To minimize the effect of pet avoidance and focus on an early period of life, we brought our attention into cat or dog exposure in the first year of life, when pet avoidance because of respiratory/allergic problems of the newborn child is less likely and exposure to the determinants of atopic disease may be crucial for the subsequent onset of the disease. Also, family history of respiratory or allergic symptoms was taken into account in the analysis. The purpose of this investigation was to determine the effects of exposure to cat or dog in the first year of life on respiratory and allergic symptoms at the age of 6-7 yr in children enrolled in a large Italian multicentre study.

\section{Methods}

This study was part of the SIDRIA-2 Study (Studi Italiani sui Disturbi Respiratori dell'Infanzia e l'Ambiente 2002), a large multicentre survey carried out in Italy in 2002 in the 
framework of the International Study of Asthma and Allergies in Childhood (ISAAC) Project (16).

The methods have been already fully described in previous publications by our group (17-19). Briefly, the study involved children in the first and second grade from 235 elementary schools, living in five areas of Northern Italy (Turin, Milan, Mantova, Trento, Emilia-Romagna Region), four areas of Central Italy (Florence, Empoli, Siena, Colleferro) and two areas of Southern Italy (Bari, Palermo). Each area was required to sample at least 1000 subjects. A random sample was extracted from the total number of schools in each area, weighted for the number of children attending the school. If the number of subjects to enroll was equal to or $<25 \%$ of the population, or if there was marked urban or geographic heterogeneity in the area under study, stratification was performed before sampling. Approval for this study was obtained from the Bioethics Committee of the Catholic University of Rome.

\section{Respiratory and allergic symptoms}

Information on respiratory and allergic symptoms of the children was collected using selfadministered questionnaires completed by parents at home. The respiratory and allergic symptoms studied in this investigation were: (i) current wheezing: wheeze or whistles in the chest during the previous 12 months; (ii) current asthma: presence of (1) asthma or hospitalization because of asthma or use of asthma medication during the previous 12 months; or (2) asthma ever in life and presence in the previous 12 months of: wheezing or exercise-induced wheezing or shortness of breath with wheezing or dry cough at night or chest tightness with wheezing; (iii) current rhinoconjunctivitis: frequent sneezes or runny/stuffy nose, out of common cold/flu with itching/watery eyes, in the previous 12 months; (iv) eczema: skin reddening with itching, at least once in life, in one or more of the following sites: elbow folds, back of the knees, ankles, under the gluteus zone, around the neck, around the ears or around the eyes; (v) cough/phlegm: presence of cough and/or phlegm for at least 4 days a week for at least 3 months in the year out of common cold/flu.

Information was also obtained on parental education, as a proxy of socioeconomic status, family history (mother, father, siblings) of asthma or /rhinoconjunctivitis or eczema, breastfeeding ( $\leq 3$ or $>3$ months), lower respiratory infections (bronchiolitis or bronchitis or pneumonia) during the first $2 \mathrm{yr}$ of life and day-care attendance during the first $3 \mathrm{yr}$ of life.

\section{Pet exposure and indoor confounders}

The presence of dogs and cats at home was assessed from the questionnaires using the questions: 'Has your child ever had a dog at home?'; 'Has your child ever had a cat at home?' For each question the possible answers were: 'Never', 'During the first year of life', 'In the past 12 months', 'In other periods'. To focus on pet exposure in the first year of life, children who had a positive answer for the category 'During the first year life' and one or more of the other possible categories were classified as in the category 'During the first year of life' only. For the same purpose, the category 'In the past 12 months' was merged with the category 'In other periods'.

Information on possible indoor confounders or effect modifiers was also collected. Information on mould exposure was obtained using the questions: 'Have you ever seen mould/dampness/ fungi on the walls or on the ceiling of your child's bedroom in the first year of your child's life?'; 'Currently?' In children, current passive smoking exposure was assessed through the question 'Are there smokers at home?' Parents were also asked if they had a gas water heater at home. Information was also collected on maternal smoking during the child's first year of life.

\section{Statistical analysis}

Statistical analysis was performed using the Statistical Package for Social Sciences (SPSS) (SPSS Inc., Chicago, IL, USA), release 10. The analyses performed were frequency distribution, chi-square test, and logistic regression analysis. Multivariate logistic regression models to assess the relationship between pet exposure and the single respiratory and allergic symptoms were built including in the analysis the confounders that were significantly associated with the outcomes in the bivariate analysis and the risk factors that the literature reported to be potential confounders. The models were further adjusted for the interactions between dog or cat ownership and the risk factors that were significantly associated with pet ownership in the bivariate analysis.

\section{Results}

Information was collected on 20,016 children (response rate 89\%). Mean (s.d.) age was 6.7 (0.7) $\mathrm{yr}$ and the proportion of males was $51.4 \%$. 
A total of $52.6 \%$ of children were resident in northern Italy, $32.7 \%$ in central Italy and $14.8 \%$ in southern Italy. Other details of the sample characteristics have been reported elsewhere (1719).

Table 1 shows the respiratory and allergic symptoms of the children, along with subject history of breastfeeding, early lower respiratory infections and day-care attendance, and family history of respiratory and allergic symptoms. In children current wheeze was $7.9 \%$, current asthma $6.7 \%$, current rhinoconjunctivitis $6.5 \%$, eczema $9.9 \%$, cough $/$ phlegm $2.9 \%$. Asthma was similarly distributed among mothers, fathers, and siblings. The prevalence of eczema was higher in mothers than in the other first-degree relatives, while the prevalence of rhinoconjunctivitis was lower in siblings than in the mothers or fathers (Table 1).

In Table 2 the presence of cats and dogs in the houses of children at different times in life is reported. In general, cats and dogs were present in similar proportions in Italian houses. Considering together the exposed children, a total of 3444 children $(17.2 \%)$ had ever had a dog and 3484 children $(17.4 \%)$ had ever had a cat at home, while 1197 children $(6.0 \%)$ had ever had both pets at home. A total of 252 children $(1.3 \%)$ had always had a dog and 263 children $(1.3 \%)$ had always had a cat at home, while those who had had a pet at home only during the first year of life were $805(4.0 \%)$ for dog and $646(3.2 \%)$ for cat. The proportion of children with a dog or

Table 1. Characteristics of the sample: symptoms and history

\begin{tabular}{lc}
\hline & $n(\%)$ \\
\hline Current wheeze & $1575(7.9)$ \\
Current asthma & $1343(6.7)$ \\
Current rhinoconjunctivitis & $1307(6.5)$ \\
Eczema & $1977(9.9)$ \\
Cough/phlegm & $575(2.9)$ \\
Breastfeeding $>3$ months & $9628(49.3)$ \\
Lower respiratory infections first 2 yr & $7622(38.1)$ \\
Day-care attendance first 3 yr & $5652(28.9)$ \\
Family history of asthma & \\
$\quad$ Mother & $1296(6.7)$ \\
Father & $1293(7.1)$ \\
Siblings & $1423(8.2)$ \\
Family history of rhinoconjunctivitis & \\
$\quad$ Mother & $3342(17.4)$ \\
Father & $3004(16.4)$ \\
Siblings & $1665(9.7)$ \\
Family history of eczema & \\
Mother & $2525(13.2)$ \\
Father & $1312(7.2)$ \\
Siblings & $1735(10.0)$ \\
$\quad$ Mother & \\
\hline & $7866(40.4)$ \\
\hline & $8845(45.6)$ \\
\hline
\end{tabular}

Table 2. Characteristics of the sample: exposure to pets, moulds, and indoor pollutants

\begin{tabular}{lc}
\hline & $\mathrm{n}(\%)$ \\
\hline Dog & \\
Never & $16572(82.8)$ \\
In the 1st year of life & $1555(7.8)$ \\
In other periods only & $1889(9.4)$ \\
Cat & \\
$\quad$ Never & $16532(82.6)$ \\
In the 1st year of life & $1383(6.9)$ \\
In other periods only & $2101(10.5)$ \\
Maternal smoking first year & $3529(17.6)$ \\
Current passive smoking & $6438(32.2)$ \\
Moulds & $3876(20.9)$ \\
Gas water heater & $4500(22.5)$ \\
\hline
\end{tabular}

a cat at home during the first year of life was not different in those with a positive family history of asthma/rhinitis/eczema with respect to those with a negative family history $(7.8 \%$ vs. $7.4 \%$ for $\mathrm{dog}$, $p=0.270 ; 7.0 \%$ vs. $6.6 \%$ for cat, $p=0.298$ ).

The prevalence of possible indoor confounders or effect modifiers, such as moulds in bedrooms, maternal smoking in the first year of life, current passive smoking and gas water heaters, is also shown in Table 2. Children were intensively exposed to current passive smoking $(32.2 \%)$.

Fig. 1 shows the prevalences of symptoms/ diagnoses by cat or dog exposure at different times in life. Dog exposure in the first year of life was not significantly associated with respiratory and allergic symptoms at age 7 , while cat exposure in the first year of life was significantly associated with current wheezing and current rhinoconjunctivitis at age $7(\mathrm{p}<0.05)$.

Bivariate analyses showing the associations between potential confounders and respiratory/ allergic symptoms/diseases are reported in Table 3. To evaluate possible confounding effects in the association between dog or cat exposure and health outcomes, we also assessed the relationships between the considered risk factors and exposure to dog or cat. The prevalence of exposure to dog was significantly higher in children with less (i.e., $\leq 8 \mathrm{yr}$ ) rather than more educated mothers or fathers $(9 \%$ vs. $7 \%$ and $12 \%$ vs. $8 \%$ for dog in the first year and in other periods, respectively, $\mathrm{p}$ for trend $<0.001$ ), children exposed rather than unexposed to moulds $(9 \%$ vs. $7 \%$ and $11 \%$ vs. $9 \%, p<0.001)$, children with current passive smoking (11\% vs. $6 \%$ and $14 \%$ vs. $8 \%, p<0.001)$ and with maternal smoking in the first year of life (12\% vs. $7 \%$ and $14 \%$ vs. $9 \%, p<0.001)$, children with a cat ever in life $(17 \%$ vs. $6 \%$ and $18 \%$ vs. $8 \%$, $\mathrm{p}<0.001$ ), children who attended a day-care school rather than those who did not (9\% vs. $7 \%$ 


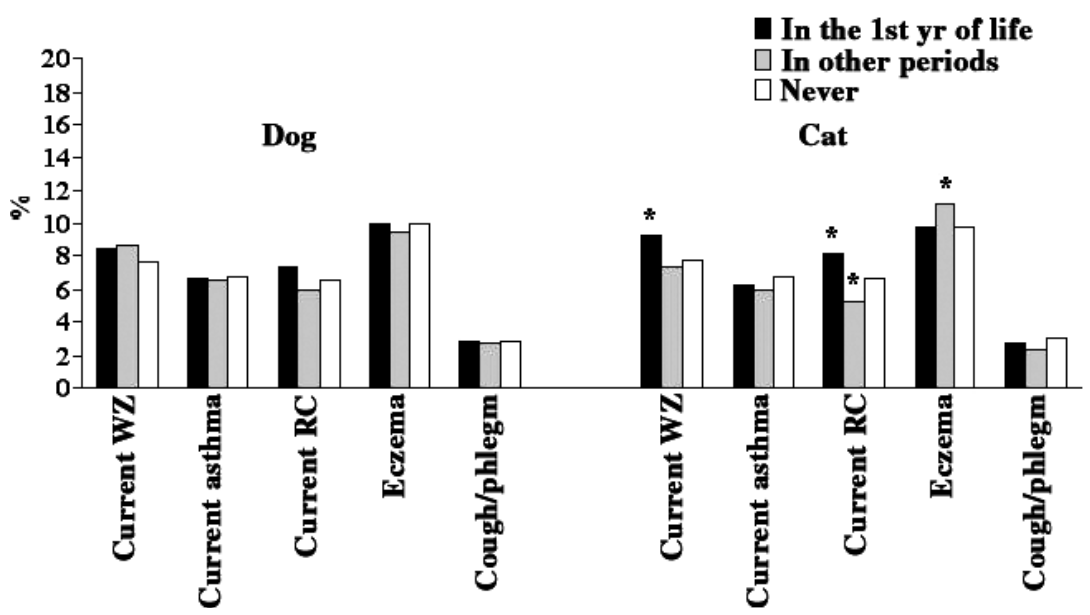

Fig. 1. Prevalence $(\%)$ of symptoms/diagnoses by exposure to cat or dog. *p by $\chi^{2}$ $<0.05$ (reference category, never exposed); WZ, wheeze; RC, rhinoconjunctivitis.

Table 3. Associations between potential confounders and respiratory/allergic symptoms/diseases

\begin{tabular}{llllll}
\hline Factor & \multicolumn{1}{c}{$\begin{array}{c}\text { Current } \\
\text { Current wheeze }\end{array}$} & \multicolumn{1}{c}{$\begin{array}{c}\text { Current asthma } \\
\text { rhinoconjunctivitis }\end{array}$} & Eczema & \multicolumn{1}{c}{ Cough/phlegm } \\
\hline Female gender & $0.70(0.63-0.78)^{* * *}$ & $0.65(0.58-0.73)^{* * *}$ & $0.72(0.64-0.81)^{* * *}$ & $1.10(1.00-1.20)^{*}$ & $0.79(0.67-0.94)^{* *}$ \\
Age & $0.95(0.87-1.03)$ & $1.07(0.98-1.17)$ & $1.12(1.03-1.22)^{* *}$ & $0.92(0.85-0.99)^{*}$ & $1.03(0.91-1.17)$ \\
Questionnaire compiler: only mother & $1.34(1.20-1.49)^{* * *}$ & $1.45(1.29-1.63)^{* * *}$ & $1.36(1.21-1.53)^{* * *}$ & $1.33(1.21-1.47)^{* * *}$ & $1.24(1.05-1.48)^{*}$ \\
Mother education >8 yr & $0.92(0.83-1.03)$ & $1.03(0.92-1.15)$ & $0.95(0.84-1.06)$ & $0.86(0.78-0.95)^{* *}$ & $0.99(0.84-1.18)$ \\
Father education >8 yr & $1.04(0.94-1.16)$ & $1.14(1.02-1.28)^{* *}$ & $1.02(0.91-1.15)$ & $0.97(0.88-1.10)$ & $1.15(0.97-1.36)$ \\
Season of interview: spring & $1.06(0.94-1.20)$ & $1.13(1.00-1.29)^{B L}$ & $1.04(0.91-1.19)$ & $0.98(0.87-1.10)$ & $1.17(0.97-1.42)^{B L}$ \\
Family history of asthma/rhinitis/eczema & $2.27(2.02-2.57)^{* * *}$ & $2.83(2.47-3.25)^{* * *}$ & $2.61(2.28-2.99)^{* * *}$ & $2.27(2.04-2.53)^{* * *}$ & $1.78(1.47-2.15)^{* * *}$ \\
Maternal smoking in the first year of life & $1.18(1.04-1.34)^{* *}$ & $1.28(1.11-1.46)^{* * *}$ & $0.97(0.84-1.13)$ & $1.07(0.95-1.21)$ & $1.53(1.27-1.86)$ \\
Current passive smoking & $0.93(0.83-1.04)$ & $1.02(0.90-1.15)$ & $0.90(0.80-1.02)^{B L}$ & $0.97(0.88-1.07)$ & $1.19(0.97-1.46)$ \\
Breastfeeding >3 months & $0.97(0.87-1.07)$ & $0.92(0.82-1.03)$ & $1.03(0.92-1.15)$ & $1.20(1.09-1.32)^{* * *}$ & $0.94(0.79-1.11)$ \\
Lower respiratory infections first 2 yr & $3.20(2.87-3.56)^{* * *}$ & $4.09(3.63-4.61)^{* * *}$ & $1.77(1.58-1.98)^{* * *}$ & $1.58(1.44-1.73)^{* * *}$ & $1.29(1.06-1.55)^{* *}$ \\
Day-care first 3 yr & $0.97(0.87-1.09)$ & $0.99(0.88-1.12)$ & $0.98(0.86-1.11)$ & $1.16(1.05-1.28)^{* *}$ & $0.940 .79-1.11)$ \\
Gas boiler & $1.03(0.91-1.17)$ & $1.05(0.92-1.19)$ & $1.13(1.00-1.29)^{B L}$ & $1.04(0.94-1.17)$ & $0.95(0.79-1.15)$ \\
Mould exposure & $1.72(1.53-1.94)^{* * *}$ & $1.63(1.43-1.85)^{* * *}$ & $1.40(1.23-1.60)^{* * *}$ & $1.39(1.24-1.55)^{* * *}$ & $2.10(1.78-2.48)$ \\
\hline
\end{tabular}

Crude odds ratios ( $95 \%$ confidence interval) by bivariate analyses.

$\mathrm{BL}$, border-line significant $0.05<\mathrm{p}<0.1 ;{ }^{*} \mathrm{p}<0.05 ;{ }^{* *} \mathrm{p}<0.01 ;{ }^{* * *} \mathrm{p}<0.001$.

for dog in the first year, $\mathrm{p}<0.05)$ and, finally, children with rather than without lower respiratory infections in the first $2 \mathrm{yr}$ of life $(11 \% \mathrm{vs}$. $9 \%$ for dog in other periods, $\mathrm{p}<0.001)$. When exposure to cat was dealt with, its prevalence was significantly higher in children exposed rather than unexposed to moulds ( $9 \%$ vs. $7 \%$ and $12 \%$ vs. $10 \%$ for cat in the first year and in other periods, respectively, $\mathrm{p}<0.001)$, those currently exposed to passive smoke ( $8 \%$ vs. $7 \%$ and $13 \%$ vs. $10 \%, \mathrm{p}<0.001)$, those whose mothers smoked in the first year of life (9\% vs. $6 \%$, and $13 \%$ vs. $10 \%, \mathrm{p}<0.001)$, those who had a dog at home ever in life $(15 \%$ vs. $5 \%$ and $19 \%$ vs. $9 \%, \mathrm{p}<0.001)$ and children who attended a day-care school rather than those who did not ( $8 \%$ vs. $7 \%$ and $11 \%$ vs. $10 \%, p<0.001)$.

A logistic regression analysis was performed taking into account cat or dog exposure at different times in life and adjusting for gender, age, area of residence, questionnaire compiler, interview season, parental education, cat exposure, mould exposure, current passive smoking, maternal smoking during the first year of life, presence of a gas water heater at home, day-care attendance during the first $3 \mathrm{yr}$ of life, lower respiratory infections (bronchiolitis/bronchitis/ pneumonia) in the first $2 \mathrm{yr}$ of life, breastfeeding, and family history of asthma/rhinitis/ eczema.

The results for dog exposure are shown in Table 4. Neither significant effects of dog exposure in the first year of life nor in other periods were found on respiratory and allergic symptoms after adjusting for the other covariates. No substantial changes were found when the models were further adjusted for the interactions between dog exposure categories and maternal education, paternal education, exposure to moulds, current passive smoking, maternal smoking during the first year of life, cat ownership ever in life, breastfeeding, day-care atten- 
Table 4. Crude and adjusted associations between exposure to dog at different times in life and respiratory or allergic symptoms (reference category: "never exposed') (valid cases in the adjusted models $n=14717$ )

\begin{tabular}{|c|c|c|c|c|}
\hline Symptom/diagnosis & Dog at home & Crude OR $(95 \% \mathrm{CI})$ & Adjusted* OR (95\% CI) & Adjusted $†$ OR $(95 \% \mathrm{CI})$ \\
\hline \multirow[t]{2}{*}{ Current wheeze } & In the 1 st year of life & $1.11(0.92-1.34)$ & $1.02(0.81-1.28)$ & $0.95(0.53-1.73)$ \\
\hline & In other periods only & $1.15(0.97-1.36)$ & $0.97(0.78-1.20)$ & $1.01(0.58-1.76)$ \\
\hline \multirow[t]{2}{*}{ Current asthma } & In the 1 st year of life & $0.97(0.79-1.20)$ & $0.80(0.62-1.05)$ & $0.63(0.29-1.38)$ \\
\hline & In other periods only & $0.96(0.79-1.17)$ & $0.86(0.68-1.09)$ & $1.04(0.54-1.98)$ \\
\hline \multirow[t]{2}{*}{ Current rhinoconjunctivitis } & In the 1 st year of life & $1.14(0.93-1.39)$ & $1.02(0.79-1.31)$ & $0.99(0.54-1.83)$ \\
\hline & In other periods only & $0.91(0.75-1.12)$ & $0.92(0.73-1.17)$ & $0.70(0.38-1.29)$ \\
\hline \multirow[t]{2}{*}{ Eczema } & In the 1st year of life & $1.00(0.84-1.19)$ & $0.99(0.81-1.21)$ & $0.74(0.44-1.24)$ \\
\hline & In other periods only & $0.95(0.81-1.12)$ & $0.89(0.73-1.07)$ & $0.83(0.51-1.36)$ \\
\hline \multirow[t]{2}{*}{ Cough/phlegm } & In the 1 st year of life & $1.00(0.74-1.37)$ & $0.98(0.68-1.43)$ & $0.98(0.37-2.57)$ \\
\hline & In other periods only & $0.95(0.71-1.27)$ & $0.89(0.62-1.28)$ & $1.01(0.40-2.55)$ \\
\hline
\end{tabular}

*Models adjusted for gender, age, area of residence, questionnaire compiler, interview season, parental education, cat exposure, mould exposure, current passive smoking, maternal smoking during the first year of life, presence of a gas water heater at home, day-care attendance during the first 3 yr of life, lower respiratory infections (bronchiolitis/bronchitis/pneumonia) in the first $2 \mathrm{yr}$ of life, breastfeeding, and family history of asthma/rhinitis/eczema.

$†$ Models with further adjustment for interactions between dog exposure categories and maternal education, paternal education, exposure to moulds, current passive smoking, maternal smoking during the first year of life, cat ownership ever in life, breastfeeding, day-care attendance during the first 3 yr of life, lower respiratory infections (bronchiolitis/bronchitis/pneumonia) during the first 2 yr of life.

dance during the first 3 yr of life, lower respiratory infections (bronchiolitis/bronchitis/pneumonia) during the first $2 \mathrm{yr}$ of life.

The results for cat exposure are shown in Table 5. Cat exposure in the first year of life was significantly and independently associated with current wheezing [OR $(95 \% \mathrm{CI}) 1.35$ (1.08-1.68), $\mathrm{p}<0.01]$ and current rhinoconjunctivitis [OR $\left(\begin{array}{llll}95 \% & \text { CI }\end{array} 1.38 \quad(1.08-1.75), \quad p<0.01\right]$ after adjusting for the other covariates. No other effects of cat exposure were found on respiratory and allergic symptoms. After further adjustment for the interactions between cat exposure categories and exposure to moulds, current passive smoking, maternal smoking during the first year of life, dog ownership ever in life, day-care attendance during the first $3 \mathrm{yr}$ of life, cat exposure in the first year of life was significantly and independently associated with current wheezing $\quad\left[\begin{array}{lllll}\mathrm{OR} & (95 \% & \mathrm{CI}) & 1.88 & (1.33-2.68) \text {, }\end{array}\right.$ $\mathrm{p}<0.001]$ and current asthma [1.74 (1.10$2.78), \mathrm{p}<0.05]$ and border-line associated with current rhinoconjunctivitis [1.43 (0.97-2.11), $\mathrm{p}=0.07]$.

To overcome the possible effects of the partial overlapping between early pet exposure and late pet exposure, we repeated the analysis using pet exposure in the first year of life and late pet exposure as two separate variables, thus adjusting pet exposure in the first year of life by pet exposure in the subsequent years. The results were very similar, having dog exposure in the first year of life an OR $(95 \%$ CI) of $1.04(0.82-1.32)$ for current wheeze, $0.88(0.67-1.15)$ for current asthma, 1.09 (0.84-1.42) for current rhinoconjunctivitis, $1.05(0.85-1.29)$ for eczema and 1.11 (0.75-1.63) for cough/phlegm, while children who had had a cat at home during the first year

Table 5. Crude and adjusted associations between exposure to cat at different times in life and respiratory or allergic symptoms (reference category: 'never exposed') (valid cases in the adjusted models $n=14717$ )

\begin{tabular}{|c|c|c|c|c|}
\hline Symptom/diagnosis & Dog at home & Crude OR (95\% CI) & Adjusted $†$ OR (95\% Cl) & Adjusted $\ddagger$ OR $(95 \% \mathrm{CI})$ \\
\hline \multirow[t]{2}{*}{ Current wheeze } & In the 1st year of life & $1.21(1.00-1.47)^{*}$ & $1.35(1.08-1.68)^{* *}$ & $1.88(1.33-2.68)^{* * *}$ \\
\hline & In other periods only & $0.93(0.78-1.11)$ & $0.97(0.79-1.20)$ & $0.84(0.59-1.20)$ \\
\hline \multirow[t]{2}{*}{ Current asthma } & In the 1st year of life & $0.91(0.73-1.15)$ & $1.08(0.83-1.41)$ & $1.74(1.10-2.78)^{*}$ \\
\hline & In other periods only & $0.86(0.71-1.04)$ & $0.92(0.73-1.17)$ & $0.99(0.64-1.53)$ \\
\hline \multirow[t]{2}{*}{ Current rhinoconjunctivitis } & In the 1 st year of life & $1.26(1.03-1.54)^{* *}$ & $1.38(1.08-1.75)^{* *}$ & $1.43(0.97-2.11)^{\mathrm{BL}}$ \\
\hline & In other periods only & $0.80(0.66-0.98)^{*}$ & $0.86(0.68-1.09)$ & $0.96(0.66-1.41)$ \\
\hline \multirow[t]{2}{*}{ Eczema } & In the 1st year of life & $1.00(0.83-1.20)$ & $0.98(0.79-1.21)$ & $0.98(0.68-1.40)$ \\
\hline & In other periods only & $1.17(1.01-1.35)^{*}$ & $1.08(0.91-1.29)$ & $1.06(0.79-1.41)$ \\
\hline \multirow[t]{2}{*}{ Cough/phlegm } & In the 1 st year of life & $0.90(0.64-1.27)$ & $1.09(0.73-1.63)$ & $0.92(0.45-1.88)$ \\
\hline & In other periods only & $0.78(0.58-1.06)$ & $1.03(0.72-1.45)$ & $1.21(0.69-2.13)$ \\
\hline
\end{tabular}

† Models adjusted for gender, age, area of residence, questionnaire compiler, interview season, parental education, dog exposure, mould exposure, current passive smoking, maternal smoking during the first year of life, presence of a gas water heater at home, day-care attendance during the first 3 yr of life, lower respiratory infections (bronchiolitis/bronchitis/pneumonia) in the first 2 yr of life, breastfeeding, and family history of asthma/rhinitis/eczema.

†odels with further adjustment for interactions between cat exposure categories and exposure to moulds, current passive smoking, maternal smoking during the first year of life, dog ownership ever in life, day-care attendance during the first $3 \mathrm{yr}$ of life.

${ }^{*} p<0.05 ;{ }^{* *} p<0.01 ;{ }^{* *} p<0.001 ; B L$, border-line significant $p=0.07$. 
of life had an OR (95\% CI) of $1.36(1.08-1.72)$ for current wheeze, $1.14(0.86-1.50)$ for current asthma, 1.50 (1.17-1.93) for current rhinoconjunctivitis, $0.9(0.77-1.20)$ for eczema and 1.09 (0.72-1.67) for cough/phlegm.

\section{Discussion}

We have assessed the respiratory and allergic symptoms at the age of $7 \mathrm{yr}$ in 20,016 Italian children who had been exposed to cats or dogs in the first year of life. We found that cat exposure in the first year of life was independently associated with current wheezing, current asthma and current rhinoconjunctivitis at the age of 7 , whilst no significant associations were found between dog exposure in the first year of life and respiratory or allergic symptoms at the age of 7 .

Recently, several studies have addressed the question of the potential harmful effect of pet exposure on the development of allergic and respiratory disorders in children and adolescents. However, up to now no general agreement on this topic has been reached. We focused our attention on the first year of life in view of the importance of early life events in the natural history of the disease. Other studies have focused their attention on pet exposure during the first years of life. Our results are in accordance with a cross-sectional Swedish study on 10,851 children (2) showing that pet-keeping in the first year of age was significantly associated with wheezing, doctor-diagnosed asthma, and rhinitis at the ages from 1 to $6 \mathrm{yr}$, when adjusting for the behaviour of avoiding pets because of allergy in the family. Also, a recent cross-sectional survey on 4479 Bulgarian 2-8 yr old children showed that keeping a furred pet (cat, dog and/or rodent) during the first years of life was a significant risk factor for rhinitis on pet exposure later in life (3). Our main results are also in accordance with a Swedish study on 181 asthmatic children, aged 1-4 yr and followed for $2 \mathrm{yr}$, which showed that early exposure to cat increased the risk of allergic sensitization and further development of more severe asthma later in childhood (5). Finally, substantially in agreement with our study a recent report on two ongoing birth cohorts showed that dog ownership in early childhood was not associated with dog sensitization or allergic symptoms and diseases up to age 6, even though it was associated with a significantly lower rate of mixed pollen and inhalant sensitization (20).

In contrast, several prospective studies have found a protective effect of dogs and cats on the subsequent development of respiratory and aller- gic symptoms or allergic sensitization (7-10). The German Multicentre Allergy Study (MAS-Study) found no relation between early indoor allergen exposure (measurement of mite and cat allergens in carpet dust) and the prevalence of asthma, wheezing, and bronchial hyper-responsiveness at the age of $7 \mathrm{yr}$ (11). However, the same group found that lung function at school age was significantly reduced in children sensitized to perennial allergens (house dust mite, cat and dog hair) early in life and exposed to high levels of the respective allergens in the first $3 \mathrm{yr}$ of life, compared with non-sensitized or sensitized but less exposed children (21). In a recent prospective inner-city birth cohort study, cat ownership was a protective factor for wheeze at the age of $5 \mathrm{yr}$, despite a positive association with cat allergen sensitization (12). However, when adult subjects are considered, as in the European Community Respiratory Health Survey (ECRHS) on 18156 subjects aged 20-44 yr from Europe, North America and Oceania, De Marco et al. reported that pet ownership in childhood had a protective effect only on asthma starting at $0-10 \mathrm{yr}$ of life and not on the incidence of asthma later in life (22).

Our results about the risk of early cat exposure in children are also in agreement with the prospective study of McConnell et al. (4) on newly diagnosed asthma in adolescents, which reported a relative risk of $1.6(95 \% \mathrm{CI}: 1.0-2.5)$ from having a furry pet at home and $1.4(95 \%$ CI: 1.0-2.0) from specifically having a dog at home. The results of the present study are also substantially in agreement with the previous reports of the ISAAC study in Great Britain (1), in which the ownership of a furry pet as a significant and independent risk factor for wheezing and rhinitis in the previous 12 months was demonstrated in $2539312-14$ yr old children. Moreover, our findings are partially consistent with a large amount of analysed data in a systematic review by Apelberg et al. (6) regarding 32 articles published between 1966 and 1999, the final conclusion of which is that exposure to pets may increase the risk of asthma and wheezing in children older than $6 \mathrm{yr}$ of age. Also, the data of a Dutch study on almost 3000 primary school children as part of the ISAAC study showed that wheezing, asthma, and bronchial responsiveness were not associated with current pet ownership, whilst past pet ownership was significantly associated with asthma, suggesting pet avoidance in families with respiratory symptoms (23).

In our study exposure to cats in the first year of life was associated with current wheezing, asthma and rhinoconjunctivitis at the age of 7 . 
One possible explanation is that children exposed to cat may become sensitized to cat allergen early in life and have symptoms afterwards when reexposed (24). It has also been pointed out $(25,26)$ that high levels of cat allergen may induce tolerance and protect against wheeze in very young children, but the allergen domestic exposure, which tends to be maintained overtime within households (27), may provoke symptoms in older children predisposed to wheeze for various reasons.

As in other studies $(5,8)$, the effects we found were different for cat or dog exposure. In fact, a dose-response relationship exists between cat allergen exposure and sensitization to cat, although the allergic sensitization may be more likely to develop in children exposed to moderate levels of this allergen than in children exposed to high amounts of Fel d 1 (28), supporting that cat allergen exposure may be considered a risk factor for the development of respiratory disorders in children. On the contrary, such relationship was not found between exposure and sensitization to dog allergen and also the early dog ownership seemed to be associated with a lower risk of asthma (29).

One of the main limitations of our study is the cross-sectional study-design with information collected through questionnaire, resulting in a potential recall bias. However, it is to point out that this is a very large population-based survey and that questionnaires have been used in many other large-scale studies $(1,2,16,22,23)$. The validity of questionnaires in such studies has already been established (22). At last, as above mentioned, we decided to concentrate our analyses on pet exposure in the first year of life in view of the importance of early life events in the natural history of the disease. Indeed, the presence of a pet at home at the time of a child's birth is probably more difficult to forget than the presence of a pet in the subsequent years. This is also the reason why we focused on pet ownership during the first year of life irrespective of pet ownership at any other time afterwards, in the attempt to minimize the effects of a potential recall bias.

Another possible limitation of this study is the potential presence of selective pet avoidance in families with allergic or respiratory symptoms. This is a common problem in studies assessing the relationship between pet exposure and symptoms $(2,6,22,23)$. It has been shown that the distribution of pet keeping in the population is largely explained by avoidance behaviour, i.e. those who keep pets are mainly those who can stand them, which results in a 'healthy pet- keeping effect' $(2,23)$. It has been recently confirmed that a part of the protective effects of owing a cat in childhood on asthma and allergy can be attributed to selective avoidance, whilst avoidance was generally not observed for dogs or birds (30). However, in our study, the proportion of children with a dog or a cat at home during the first year of life was not different in those with a positive family history of asthma/rhinitis/eczema with respect to those with a negative family history.

At last, the results of this study might, at least in part, be limited by the fact that we mainly investigated the presence of pets at home. Children could actually have been exposed to cat or dog allergens in a variety of different mechanisms (passive transfer from visitors with pets, staying in relatives' homes with pets, vacation homes with pets, dander's transport in schools, etc.). Such a limitation could only be overcome in small scale studies on children with personal monitors or environmental monitors in the rooms where they live (at home, at school, etc.).

In conclusion, cat exposure in the first year of life was an independent risk factor for current wheezing, current asthma and current rhinoconjunctivitis at the age of 7 . On the contrary, no significant associations were found between dog exposure in the first year of life and respiratory or allergic symptoms at the age of 7 . These data add more information to the conflicting scenario of the results regarding the effects of cat and dog exposure in children.

\section{Funding}

This study was partially funded by the Italian Ministry of Health.

\section{Acknowledgments}

The SIDRIA-2 Collaborative Group is grateful to all schoolchildren and their parents for their participation and the teachers and school directors for their helpful collaboration. We especially thank all of the physicians and staff members of the National Health Service for their important work in the collection of data. We are grateful to Prof. Maurizio de Martino (Florence, Italy) and Prof. Duane L. Sherrill (Tucson, AZ, USA) for their excellent comments. We also thank Maria Carola Musumeci for her valuable help in revising the manuscript.

\section{References}

1. Burr ML, Anderson HR, Austin JB, et al. Respiratory symptoms and home environment in children: a national survey. Thorax 1999: 54: 27-32.

2. Bornehag CG, Sundell J, Hagerhed L, Janson S. Pet-keeping in early childhood and airway, nose and skin symptoms later in life. Allergy 2003: 58: 939-44.

3. Naydenov K, Popov T, Mustakov T, Melikov A, Bornehag C-G, Sundell J. The association of pet 


\section{Lombardi et al.}

keeping at home with symptoms in airways, nose and skin among Bulgarian children. Pediatr Allergy Immunol 2008: 19: 702-8.

4. McConnell R, Berhane K, Gilliland F, et al. Indoor risk factors for asthma in a prospective study of adolescents. Epidemiology 2002: 13: 288-95.

5. Melén E, Wickman M, Nordvall Sl, van HageHAMSTEN M, LindFORS A. Influence of early and current environmental exposure factors on sensitisation and outcome of asthma in pre-school children. Allergy 2001: 56: 646-52.

6. Apelberg BJ, Aoki Y, JaAkKola JJK. Systematic review: Exposure to pets and risk of asthma and asthma-like symptoms. J Allergy Clin Immunol 2001: 107: 455-60.

7. Remes St, Castro-Rodriguez JA, Holberg CJ, Martinez FD, Wright AL. Dog exposure in infancy decreases the subsequent risk of frequent wheeze but not of atopy. J Allergy Clin Immunol 2001: 108: 50915 .

8. Litonjua AA, Milton DK, Celedon JC, Ryan L, WeIss ST, GoLD DR. A longitudinal analysis of wheezing in young children: the independent effects of early life exposure to house dust endotoxin, allergens, and pets. J Allergy Clin Immunol 2002: 110: 736-42.

9. Perzanowski MS, Ronmark E, Platts-Mills T, LUNDBÄCK B. Effect of cat and dog ownership on sensitisation and development of asthma among preteenage children. Am J Respir Crit Care Med 2002: 166: 696702 .

10. Ownby DR, Cole Johnson C, Peterson El. Exposure to dogs and cats in the first year of life and risk of allergic sensitization at 6 to 7 years of Age. JAMA 2002: 288: 963-72.

11. Lau S, Illi S, Sommerfield C, et al. Early exposure to house-dust mite and cat allergens and the development of childhood asthma: a cohort study. Lancet 2000: 356: 1392-7.

12. Perzanowski MS, Chew GL, Divjan A, et al. Cat ownership is a risk factor for the development of anticat $\operatorname{IgE}$ but not current wheeze at age 5 years in an inner-city cohort. J Allergy Clin Immunol 2008: 121: 1047-52.

13. Kurukulaaratchy RJ, Matthews S, Arshad SH. Relationship between childhood atopy and wheeze: what mediates wheezing in atopic phenotypes? Ann Allergy Asthma Immunol 2006: 97: 84-91.

14. Kurukulaaratchy RJ, Matthews S, Arshad SH. Defining childhood atopic phenotypes to investigate the association of atopic sensitization with allergic disease. Allergy 2005: 60: 1280-6.

15. von Mutius E, Schmid S, PASTURE Study Group. The PASTURE project: EU support for the improvement of knowledge about risk factors and preventive factors for atopy in Europe. Allergy 2006: 61: 407-13.

16. Asher MI, KeIL U, ANDERson HR, et al. International Study of Asthma and Allergies in Childhood (ISAAC): rationale and methods. Eur Respir J 1995: 8: 483-91.
17. Simoni M, Lombardi E, Berti G, et al. Mould/dampness exposure at home is associated with respiratory disorders in Italian children and adolescents. The SIDRIA-2 Study (Studi Italiani sui Disordini Respiratori nell'Infanzia e l'Ambiente 2002). Occup Environ Med 2005: 62: 616-22.

18. Galassi C, De Sario M, Biggeri A, et al. Changes in prevalence of asthma and allergies among children and adolescents in Italy: 1994-2002. Pediatrics 2006: 117: 34- 42.

19. Migliore E, Pearce N, Bugiani M, et al. Prevalence of respiratory symptoms in migrant children to Italy: the results of SIDRIA-2 study. Allergy 2007: 62: 293-300.

20. Chen CM, Morgenstern V, Bischof W, et al. Dog ownership and contact during childhood and later allergy development. Eur Respir J 2008: 31: 963-73.

21. Illi S, von Mutius E, LAu S, et al. Perennial allergen sensitisation early in life and chronic asthma in children: a birth cohort study. Lancet 2006: 368: 763-70.

22. De Marco R, Pattaro C, Locatelli F, Svanes C, ECRHS STUdy GROUP. Influence of early life exposures on incidence and remission of asthma throughout life. J Allergy Clin Immunol 2004: 113: 845-52.

23. Anyo G, Brunekreef B, De Meer G, Aarts F, JansSEN NAH, VAN VLIET P. Early, current and past pet ownership: associations with sensitisation, bronchial responsiveness and allergic symptoms in school children. Clin Exp Allergy 2002: 32: 361-6.

24. Celedón JC, Litonjua AA, Ryan L, Platts-Mills T, WeISS ST, GoLD DR. Exposure to cat allergen, maternal history of asthma, and wheezing in first 5 years of life. Lancet 2002: 360: 781-2.

25. Polk S, Sunyer J, Muñoz-Ortis L, et al. A prospective study of Fel d1 and Der pl exposure in infancy and childhood wheezing. Am J Respir Crit Care Med 2004: 170: 273-8.

26. Erwin EA, Wickens K, Custis NJ, et al. Cat and dust mite sensitivity and tolerance in relation to wheezing among children raised with high exposure to both allergens.

27. Heinrich J, Holscher B, Douwes J, et al. Reproducibility of allergen, endotoxin and fungi measurements in the indoor environment. J Expo Anal Environ Epidemiol 2003: 13: 152-60.

28. Liccardi G, D'Amato G, Russo M, et al. Focus on cat allergen (Fel d 1): immunological and aerodynamic characteristics, modality of airway sensitization and avoidance strategies. Int Arch Allergy Immunol 2003: 132: $1-12$

29. Lindfors A, van Hage-Hamsten M, Rietz H, WickMAN M, NordVall SL. Influence of interaction of environmental risk factors and sensitization in young asthmatic children. J Allergy Clin Immunol 1999: 104: 755-62.

30. Svanes C, Zock JP, Anto J, et al. Do asthma and allergy influence subsequent pet keeping? An analysis of childhood and adulthood. J Allergy Clin Immunol 2006: 118: 691-8. 